\title{
Fracture Resistance of Residually-Stressed Ceramic Laminated Structures
}

\author{
G. A. Gogotsi, N. I. Lugovoi, and V. N. Slyunyaev
}

Pisarenko Institute of Problems of Strength, National Academy of Sciences of Ukraine, Kiev, Ukraine

УДК 539.4

\section{Сопротивление разрушению внутренне напряженных слоистых керамических структур}

\author{
Г. А. Гогоци, Н. И. Луговой, В. Н. Слюняев
}

Институт проблем прочности им. Г. С. Писаренко НАН Украины, Киев, Украина

Изучено влияние остаточных напряжений на сопротивление разруиению и остановку треиины в несимметричных слоистьх структурах $\mathrm{Si}_{3} \mathrm{~N}_{4} / \mathrm{Si}_{3} \mathrm{~N}_{4}-\mathrm{TiN}$. Оиенена методика определения $R$-кривыз слоистьхх композитов с использованием метода податливости. Разработан аналитический метод расчета зависимости сопротивления разруиению от длинь трещины в слоистьх структурах со слоями, имеющими различные упругие характеристики. Приленилость метода проверена путем расчета коэффициентов интенсивности напряжений для слоистьхх образиов с краевой тречиной. Полученные результаты сопоставлялись с данныли механических испьтаний.

Ключевые слова: слоистая структура, вязкость разрушения, моделирование, остановка трещины, остаточные напряжения.

Introduction. Multilayered ceramic-matrix composites (MCMC) have a wide variety of applications in modern technology. Layers comprising ceramic materials are extensively used in engineering structural components with the objective to improve the mechanical, thermal, chemical and tribological performance. Recent research and developments in the area of MCMC seek to utilize the materials in such diverse applications as surface coatings, thermal barrier protection for turboengines, valves in reciprocating engines for automobiles and cutting tools.

Despite of many attractive properties such as high hardness and high temperature stability, MCMC have the major disadvantage of lacking reliability and sensitivity to surface contact damage. The last factor can lead to strength reduction and even to catastrophic failure.

A number of strategies have been developed in recent years to design tough and strong MCMC [1]. These include designing weak interfaces for crack deflection [2], using residual compression in surface layers [3], designing crack bifurcation effect in compressive layers [4], and controlling the frontal shape of the transformation zones in zirconia ceramics [5]. These mechanisms should 
provide an arrest of crack in layered structure, increasing consequently its reliability. The reliability of the MCMC can be improved also by controlling the size of flaws introduced into the material during processing. This may be achieved by dispersion of a slurry of the designated power and by its passing through a filter. As a result only heterogeneities with sizes smaller than a critical size can pass through, depending on the filter fineness. Drawback of this procedure is its expensiveness. Besides, such material is still subject to damage during machining with the reliability degraded accordingly.

In multilayered materials with strong interfaces the differences in the coefficients of thermal expansion (CTE's) between dissimilar materials or phase transformation in layers inevitably generate thermal residual stresses during subsequent cooling [6]. The essential feature of residual stress distribution in a layered structure is its arising on a macroscopic scale. The relative thickness of different layers determines the relative magnitudes of compressive and tensile stresses, while the magnitude of the strain mismatch between the layers dictates the absolute values of the residual stresses. Control of the thermal stresses and the accompanying changes in structure are important to ensure the structural integrity of the layered components.

A key feature that imparts good mechanical properties in the multilayer systems is the ability to be toughened significantly by placing their surfaces in residual compression and to arrest crack. It was shown in [3] that a residual surface compression of $\sim 500 \mathrm{MPa}$ in a surface layer of three-layered alumina-zirconia specimen can increase its fracture toughness by a factor of 7.5 (up to $30 \mathrm{MPa} \cdot \mathrm{m}^{1 / 2}$ ) for edge-crack lengths of the order of the surface-layer thickness. The toughening derived from macroscopic surface compression was in fact a crack shielding phenomenon and the fracture toughness increase was equivalent to crack growth resistance $(R)$ behavior [7]. The $R$-behavior is often connected with bridging mechanism. The mechanism is associated with the closure stress field that acts behind the tip of the advancing crack [8]. However, there are some differences related to bridging mechanism (this is typical for non-layered ceramics) and the shielding phenomenon in layered structures. Firstly, while bridging mechanism gives rise to dependence of fracture resistance only on crack length increment, the shielding effect results in that of fracture resistance on overall crack length [3, 7, 9]. Secondly, as a rule the bridging mechanism promotes fracture resistance increasing with crack advance whereas the shielding effect can induce both improvement and deterioration of fracture resistance depending on crack tip location in tensile or compressive layer.

Actually layered specimen fracture resistance measured experimentally is the apparent fracture toughness. This is due to superposition of different effects like residual stress shielding and structure in-homogeneity. In fracture mechanics, one usually includes stresses in the crack driving force; however it is sometimes useful to consider residual stresses as part of the crack resistance. Thus, a higher resistance to failure for layered structure with residual stress is obtained from a reduction of the crack driving force rather than from an increase in the intrinsic material resistance to crack extension [9].

Despite numerous experimental and theoretical studies of fracture resistance of MCMC, systematic researches of $R$-behavior and of crack arresting in layered 
composites are very scarce. A great number of publications are dealing with symmetrical layered structure. This is an idealized situation. In fact, laminates are characterized by some dissymmetry of their architecture due to random deviations in fabrication process. Moreover, specific non-symmetrical layered structures are important in some engineering applications. Conventional analytical consideration of shielding effect in laminate also neglects difference of elastic moduli of layers $[3,7]$. However, effect of different moduli on fracture resistance of laminates is not so negligible. The influence of elastic moduli variation across a layered sample on $R$-curve behavior is investigated in [10]. It was shown that the elastic moduli difference affects residual stress distribution and has consequently a significant influence on the measured $R$-curve behavior. But neither detailed analysis of conditions of crack arresting nor its stable/non-stable growth has been carried out in [10].

The effect of macroscopic residual stresses on fracture resistance and crack arresting in non-symmetric $\mathrm{Si}_{3} \mathrm{~N}_{4}$-based layered structures fabricated in the form of single-edge V-notch-bend (SEVNB) specimens is investigated in this study. One of aims of the work is an examination of compliance technique to study $R$-curve effect as applied to layered specimens. A special attention is paid to the development of an analytical method to calculate fracture resistance - crack length dependence in layered structures with different elastic moduli of layers. The validity of the method is examined by calculation of the stress intensity coefficients for edge-cracked layered specimens and comparing the results with the mechanical test data.

The Model. Figure 1 shows a schematic of the two-component multilayer specimen analyzed in this study. Parameter $t_{i}$ designates thickness of layer number $i$. The total thickness of specimen of rectangular cross section is $w$, its width is $b$, and the total number of layers is $N$. Choice of coordinate system is important for further consideration. It is the most appropriate to put the coordinate origin on tensile surface of bending specimen. The geometry of the multilayered material analyzed here is such that the problem can be reduced to one dimension, and that analytically tractable solutions can be used. Here, the parameters of interest in the study of mechanical behavior depend only on coordinate $x$.

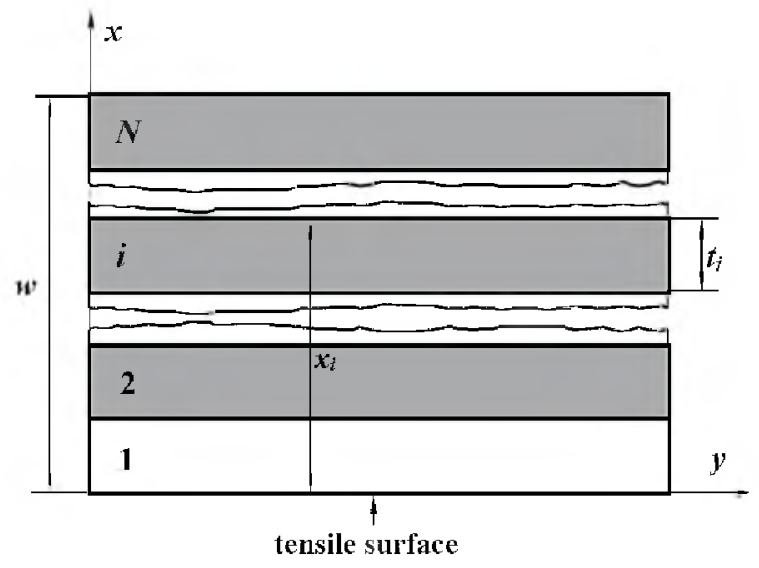

Fig. 1. Schematic of the two-component multilayer specimen. 
It was shown in $[3,11]$ that the stress intensity factor, $K_{1}$, due to an arbitrary stress distribution in the prospective crack path in the absence of the crack $\sigma(x)$, can be obtained as:

$$
K_{1}=\int_{0}^{a} h\left(\frac{x}{a}, \alpha\right) \sigma(x) d x
$$

where $x$ is the distance along the crack length measured from the surface of an edge crack, $a$ is the crack length, $\alpha=a / w$, and $w$ is the specimen thickness (Fig. 2). For edge-cracked specimens, Fett and Munz [11] have developed the following weight function:

$$
h\left(\frac{x}{a}, \alpha\right)=\frac{(2 / \pi a)^{1 / 2}}{\left(1-\frac{x}{a}\right)^{1 / 2}(1-\alpha)^{3 / 2}}\left[(1-\alpha)^{3 / 2}+\sum A_{\nu \mu}\left(1-\frac{x}{a}\right)^{\nu+1} \alpha^{\mu}\right] .
$$

The values of the coefficients $A_{v \mu}$ and the exponents $v$ and $\mu$ in (2) are listed in Table 1.

$\mathrm{T}$ a b 1 e 1

Values of coefficients $A_{v \mu}$ in Eq. (2) [11]

\begin{tabular}{|c|c|c|c|c|c|}
\hline \multirow{2}{*}{$v$} & \multicolumn{5}{|c|}{$A_{\nu \mu}$} \\
\cline { 2 - 6 } & $\mu=0$ & $\mu=1$ & $\mu=2$ & $\mu=3$ & $\mu=4$ \\
\hline 0 & 0.498 & 2.4463 & 0.07 & 1.3187 & -3.067 \\
\hline 1 & 0.54165 & -5.0806 & 24.3447 & -32.7208 & 18.1214 \\
\hline 2 & -0.19277 & 2.55863 & -12.6415 & 19.763 & -10.986 \\
\hline
\end{tabular}

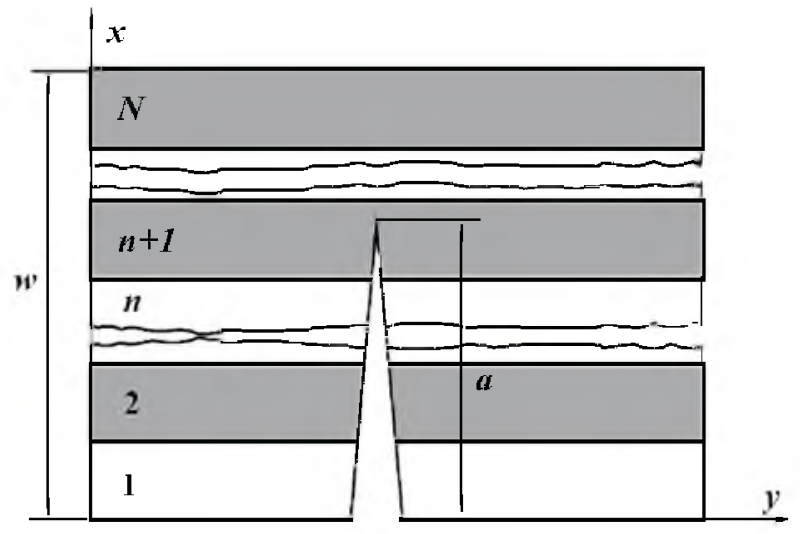

Fig. 2. Schematic of analyzed crack location in layered specimen.

In the case where deformation is a function of coordinate $x$ only, it follows from the strain compatibility [12] that overall deformation $\varepsilon(x)$ must be linear for elastic material: 


$$
\varepsilon(x)=\varepsilon_{0}+k x .
$$

Here $\varepsilon_{0}$ is the deformation at $x=0$, and $k$ is the specimen curvature. An equal biaxial stressed state is known to be the most appropriate approximation to describe the stressed state in real layered specimens [13]. This is the case of infinite dimensions along directions $y$ and $z$, but with finite value of specimen thickness. In the equal biaxial stressed state we have: $\varepsilon(x)=\varepsilon_{z z}=\varepsilon_{y y}, \sigma(x)=$ $=\sigma_{z z}=\sigma_{y y}$, where $\varepsilon_{z z}, \varepsilon_{y y}, \sigma_{z z}$, and $\sigma_{y y}$ are strain and stress components along $z$ - and $y$-axis respectively. Edge effects (occurrence of three-dimensional stresses near the edges of layered composite over a distance from the edge which is approximately equal to the layer thickness [14]) can be neglected due to their high-localized character. Then

where

$$
\sigma(x)=E^{\prime}(x)[\varepsilon(x)-\widetilde{\varepsilon}(x)]
$$

$$
E^{\prime}(x)=E(x) /[1-v(x)]
$$

In Eqs. (4), (5), $E(x)$ and $v(x)$ are the elastic modulus and Poisson ratio distributions along $x$-axis, respectively. Value of $\widetilde{\varepsilon}(x)$ is the strain non-associated with stress. It is associated with thermal expansion or/and with a volume change due to a crystallographic phase transformation.

The static balance conditions [12] in the chosen coordinate system result in a system of linear equations with unknown values $\varepsilon_{0}$ and $k$ :

$$
\left\{\begin{array}{l}
F_{a}+\int_{0}^{w} b \sigma\left(x, \varepsilon_{0}, k\right) d k=0 \\
M_{a}+\int_{0}^{w} b x \sigma\left(x, \varepsilon_{0}, k\right) d x=0
\end{array}\right.
$$

where $F_{a}$ is the applied axial force and $M_{a}$ is the applied bending moment. Solution of the system is [13]:

$$
\begin{gathered}
\varepsilon_{0}=\frac{I_{2}\left(J_{0}-F_{a} / b\right)+I_{1}\left(J_{1}-M_{a} / b\right)}{I_{1}^{2}-I_{0} I_{2}}, \\
k=\frac{I_{1}\left(J_{0}-F_{a} / b\right)-I_{0}\left(J_{1}-M_{a} / b\right)}{I_{1}^{2}-I_{0} I_{2}},
\end{gathered}
$$

where

$$
\begin{gathered}
I_{j}=\int_{0}^{w} x^{j} E^{\prime}(x) d x \quad(j=0,1,2), \\
J_{j}=\int_{0}^{w} x^{j} \widetilde{\varepsilon}(x) E^{\prime}(x) d x \quad(j=0,1) .
\end{gathered}
$$


Note that the superposition principle is valid for this problem. It permits to express the stress variation along the crack path in a specimen as

$$
\sigma(x)=\sigma_{a}(x)+\sigma_{r}(x)
$$

where $\sigma_{a}(x)$ is the bending stress in the prospective crack path in the absence of any residual stresses, and $\sigma_{r}(x)$ is the macroscopic residual stress distribution.

In [3], the bending stress $\sigma_{a}(x)$ was expressed as follows:

$$
\sigma_{a}(x)=\sigma_{m}\left(1-\frac{2 x}{w}\right)
$$

where $\sigma_{m}$ is the applied stress on tensile surface of bending specimen. It is well known that

$$
\sigma_{m}=\frac{1.5 P S}{b w^{2}}=\frac{6 M_{a}}{b w^{2}}
$$

Here $P$ is the critical load (applied bending load corresponding to the specimen failure) and $s$ is the support span. However, the differences in the elastic moduli of the layers were not taken into account in [3]. Difference in elastic moduli of the layers result in specific distribution of the applied stress along $x$-direction. Elastic material demonstrates continuous linear distribution of the applied strain under bending. This promotes piecewise-linear distribution of the applied stress, shown schematically in Fig. 3. To derive the applied stress distribution under bending we can use expressions (3), (4), (7a), (7b), and (12), taking into account that in this case $F_{a}=0$. If only the applied stress is considered, we can take $\widetilde{\varepsilon}(x)=0$. Then it follows that the applied stress acting in the layer with number $i$ is:

$$
\sigma_{a}(x)=\frac{E_{i}^{\prime} w^{2}}{6\left(I_{L 1}^{2}-I_{L 0} I_{L 2}\right)} \sigma_{m}\left[I_{L 0} x-I_{L 1}\right], \quad x_{i-1} \leq x \leq x_{i} .
$$

Here $x_{i}$ is the coordinate of upper boundary of $i$ th layer, $E_{i}^{\prime}=E_{i} /\left(1-v_{i}\right)$, and $E_{i}$ and $v_{i}$ are the elastic modulus and Poisson ratio of layer number $i$, respectively. Values of $I_{L j}$ can be obtained from expression (8) accounting for layered structure (Fig. 1):

$$
I_{L j}=\frac{1}{j+1} \sum_{i=1}^{N} E_{i}^{\prime}\left(x_{i}^{j+1}-x_{i-1}^{j+1}\right) \quad(j=0,1,2) .
$$

Residual stress distribution can be found from Eqs. (3), (4), (7a), and (7b) taking into account that $F_{a}=0, M_{a}=0$ (Fig. 3):

$\sigma_{r}(x)=\frac{E_{i}^{\prime}}{I_{L 1}^{2}-I_{L 0} I_{L 2}}\left[I_{L 1} J_{L 1}-I_{L 2} J_{L 0}+\left(I_{L 1} J_{L 0}-I_{L 0} J_{L 1}\right) x\right], \quad x_{i-1} \leq x \leq x_{i}$, 
where $J_{L j}$ can be obtained from the expressions (9) accounting for layered structure:

$$
J_{L j}=\frac{1}{j+1} \sum_{i=1}^{N} \widetilde{\varepsilon}_{i} E_{i}^{\prime}\left(x_{i}^{j+1}-x_{i-1}^{j+1}\right) \quad(j=0,1) .
$$

Here $\widetilde{\varepsilon}_{i}$ is the strain of $i$ th layer non-associated with stress. The thermal expansion or/and a volume change due to a crystallographic phase transformation can be the source of this strain. However, the case of phase transformation is out of the scope of this paper. In case of thermal expansion $\widetilde{\varepsilon}_{i}=\int_{T_{0}}^{T_{j}} \beta_{i}(T) d T$, where $\beta_{i}(T)$ is the thermal expansion coefficient of ith layer at temperature $T$, and $T_{0}$ and $T_{j}$ are actual and "joining" temperature, respectively. During cooling of the sample the deformation difference, due to the different thermal expansion coefficients, is accommodated by creep as long as the temperature is high enough. Below a certain temperature, called the "joining" temperature, the different components become bonded together and internal stresses appear. The "joining" temperature is usually the value that is known only approximately. In practice, $T_{j}$ is generally accepted to lie somewhat below the sintering temperature. If $\beta_{i}(T)$ is a linear function, $\widetilde{\varepsilon}_{i} \leq \beta_{i}>\Delta T$, where $\Delta T=T_{j}-T_{0},<\beta_{i} \geq \frac{\beta_{i}\left(T_{0}\right)+\beta_{i}\left(T_{j}\right)}{2}$ is the average value of the thermal expansion coefficient in the temperature range from $T_{0}$ to $T_{j}$.

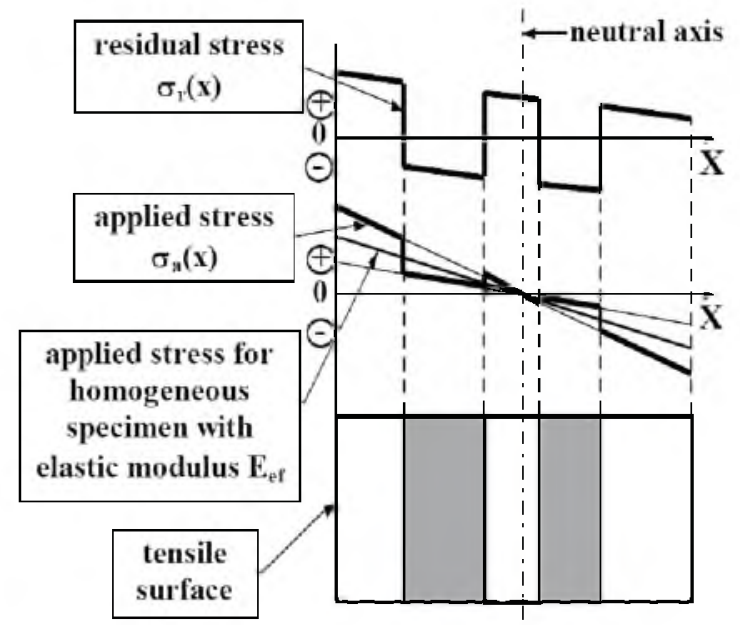

Fig. 3. Schematic of residual and applied stress distribution in layered specimen.

Using the condition of crack growth $\left(K_{1}=K_{1 c}\right.$, where $K_{1 c}$ is the fracture toughness of material) and (1), (10), we obtain:

$$
K_{1 c}=\int_{0}^{a} h\left(\frac{x}{a}, \alpha\right) \sigma_{a}(x) d x+\int_{0}^{a} h\left(\frac{x}{a}, \alpha\right) \sigma_{r}(x) d x
$$


Using Eq. (13) the first integral in (17) can be expressed for a layered material as:

$$
\begin{gathered}
\int_{0}^{a} h\left(\frac{x}{a}, \alpha\right) \sigma_{a}(x) d x=\frac{\sigma_{m} w^{2}}{6\left(I_{L 1}^{2}-I_{L 0} I_{L 2}\right)} \times \\
\times\left\{E_{n+1}^{\prime} \int_{x_{n}}^{a} h\left(\frac{x}{a}, \alpha\right)\left[I_{L 0} x-I_{L 1}\right] d x+\sum_{i=1}^{n} E_{i}^{\prime} \int_{x_{i-1}}^{x_{i}} h\left(\frac{x}{a}, \alpha\right)\left[I_{L 0} x-I_{L 1}\right] d x\right\},
\end{gathered}
$$

where $n$ is the number of layers broken by the crack (or notch) completely (Fig. 2). Using Eq. (15), the second integral in (17) for a layered material takes the form:

$$
\begin{gathered}
K_{r}=\int_{0}^{a} h\left(\frac{x}{a}, \alpha\right) \sigma_{r}(x) d x= \\
=\frac{1}{I_{L 1}^{2}-I_{L 0} I_{L 2}}\left\{E_{n+1}^{\prime} \int_{x_{n}}^{a} h\left(\frac{x}{a}, \alpha\right)\left[I_{L 1} J_{L 1}-I_{L 2} J_{L 0}+\left(I_{L 1} J_{L 0}-I_{L 0} J_{L 1}\right) x\right] d x+\right. \\
\left.+\sum_{i=1}^{n} E_{i}^{\prime} \int_{x_{j-1}}^{x_{i}} h\left(\frac{x}{a}, \alpha\right)\left[I_{L 1} J_{L 1}-I_{L 2} J_{L 0}+\left(I_{L 1} J_{L 0}-I_{L 0} J_{L 1}\right) x\right] d x\right\}
\end{gathered}
$$

Here, $K_{r}$ is the stress intensity due to the residual stresses.

The following formula is given for the stress intensity of an edge crack in the specimen under bending as being accurate to $\pm 0.2 \%$ in the range $\alpha=0$ to 1 [15]:

$$
K_{1}=\frac{P s}{b w^{3 / 2}} f_{0}(\alpha)
$$

where $f_{0}(\alpha)$ is a nondimensional stress intensity factor given by the following expression [15]:

$$
f_{0}(\alpha)=\frac{1.5 \alpha^{1 / 2}\left[1.99-\alpha(1-\alpha)\left(2.15-3.93 \alpha+2.7 \alpha^{2}\right)\right]}{(1+2 \alpha)(1-\alpha)^{3 / 2}} .
$$

Taking into account Eqs. (12), (21), expression (20) can be transformed to the form:

$$
K_{1}=Y(\alpha) \sigma_{m} a^{1 / 2},
$$

where

$$
Y(\alpha)=\frac{1.99-\alpha(1-\alpha)\left(2.15-3.93 \alpha+2.7 \alpha^{2}\right)}{(1+2 \alpha)(1-\alpha)^{3 / 2}}
$$

102 
It was shown in [3] that Eqs. (20), (22) can be successfully used to determine fracture toughness of ceramic matrix layered materials. However, it should be noted that as applied to inhomogeneous (particularly, layered) materials the equations give the so-called apparent fracture toughness. In bending test, this is the fracture toughness of some effective homogeneous specimen that meets the following conditions: 1) to have the same dimensions as real layered specimen; 2) to have notch depth equal to that of real layered specimen; 3) under the same loading conditions to demonstrate the same critical load as that for real layered specimen. In spite of relativity of this value, it is a useful characteristic allowing contributions of such factors as residual stresses and material inhomogeneity to be accounted for. Thus, experimental value of the apparent fracture toughness of layered specimen can be found using expression (22):

$$
K_{a p p}=Y(\alpha) \sigma_{m} a^{1 / 2}
$$

It follows from Eqs. (17)-(19) and (24) that apparent fracture toughness of layered composite $K_{a p p}$ can be written as:

$$
K_{a p p}=\frac{6 Y(\alpha) a^{1 / 2}\left(I_{L 1}^{2}-I_{L 0} I_{L 2}\right)\left(K_{1 c}^{(i)}-K_{r}\right)}{w^{2}\left\{E_{n+1}^{\prime} \int_{x_{n}}^{a} h\left(\frac{x}{a}, \alpha\right)\left[I_{L 0} x-I_{L 1}\right] d x+\sum_{i=1}^{n} h\left(\frac{x}{a}, \alpha\right)\left[I_{L 0} x-I_{L 1}\right] d x\right\}},
$$

where $K_{1 c}^{(i)}$ is the fracture toughness of th layer material. Expression (25) suggests that the higher resistance to fracture is derived from a reduction of the crack driving force rather than from an increase in the intrinsic resistance to crack extension.

Experimental. The choice of composition for $\mathrm{Si}_{3} \mathrm{~N}_{4}$ based ceramics laminates is determined by the coefficient of thermal expansion and Young's modulus of the compounds. Three compositions of composite layers were used: 1) $\mathrm{Si}_{3} \mathrm{~N}_{4}$ (M11, Starck, Germany); 2) $\mathrm{Si}_{3} \mathrm{~N}_{4}-20$ wt.\% TiN (grade C, Starck, Germany); 3) $\mathrm{Si}_{3} \mathrm{~N}_{4}-70$ wt.\% TiN (grade C, Starck, Germany). Young's moduli, Poisson ratios, joining temperature $T_{j}$ and average values of coefficients of thermal expansion of compositions under study are given in [16]. Mean values of intrinsic fracture toughness of monolith materials are evaluated in the work to be approximately the same for all layer compositions, being $5 \mathrm{MPa} \cdot \mathrm{m}^{1 / 2}$. Note that the intrinsic fracture toughness corresponds to fracture toughness of layer material.

Milling of mixtures of certain compositions was done in the ball mill for $5 \mathrm{~h}$. The formation of a thin ceramic layer is of specific importance, as the sizes of residual stress zones (tensile and compressive) are directly connected with the thickness of layers. Green tapes were manufactured with rolling. Rolling permits to control thickness of green layers, to obtain high green density and a rather low amount of solvent and organic additives in comparison with other methods such as a tape casting [17]. However there is a problem to produce thin tapes, 
$<100 \mu \mathrm{m}$, with a small amount of plasticizer and sufficient strength and elasticity to handle green layers after rolling.

Crude rubber ( 4 wt.\%) was added to the mixture of powders as a plastisizer through a $3 \%$ solution in petrol. Then the powders were dried up to the $2 \mathrm{wt} . \%$ residual amount of petrol in the mixture. After sieving powders with a $500 \mu \mathrm{m}$ sieve, granulated powders were dried up to the $0.5 \mathrm{wt} . \%$ residual petrol. A roll mill with $40 \mathrm{~mm}$ rolls was used for rolling. The velocity of rolling was $1.5 \mathrm{~m} / \mathrm{min}$. Working pressure varied from $10 \mathrm{MPa}$ for the relative tape density of $64 \%$ to $100 \mathrm{MPa}$ for $74 \%$ density. The thickness of green tapes was either $0.4-0.5 \mathrm{~mm}$ or $0.8-1.0 \mathrm{~mm}$, the width was $60-65 \mathrm{~mm}$. Samples of ceramics were prepared by hot pressing of tapes stacked together. The hot pressing was performed at the temperature $1780-1820^{\circ} \mathrm{C}$, with duration of $20 \mathrm{~min}$ and under the pressure of $30 \mathrm{MPa}$.

Green tapes were stacked together to form desirable layered structure. The graphite dies were used for the hot pressing without protective atmosphere. After hot pressing, the thickness of the $\mathrm{Si}_{3} \mathrm{~N}_{4}$ layers was in the range of 160-960 $\mu \mathrm{m}$, and the thickness of the $\mathrm{Si}_{3} \mathrm{~N}_{4}$ layers with TiN additive varied from 160 to $480 \mu \mathrm{m}$.

The specimens for mechanical tests were prepared from hot-pressed plates. SEVNB specimens were used for testing. The test data have confirmed that the SEVNB method can be easier applied in practice and used for the majority of advanced ceramics and ceramic particulate composites [18]. The V-notches with tip radii of an order of $10-15 \mu \mathrm{m}$ were made in the specimens by a two-stage technique. In the first stage, the specimens were notched by a diamond saw. Then sharp tip of notch was obtained using stainless steel blade and diamond abrasive. Optical photograph of a typical notch tip along with average values of calculated residual stresses acting in the layers is presented in Fig. 4. The depth of the notches was about $60-80 \%$ of the specimen thickness being $3.37-4.0 \mathrm{~mm}$. Specimens of larger thickness were ground down to such sizes.

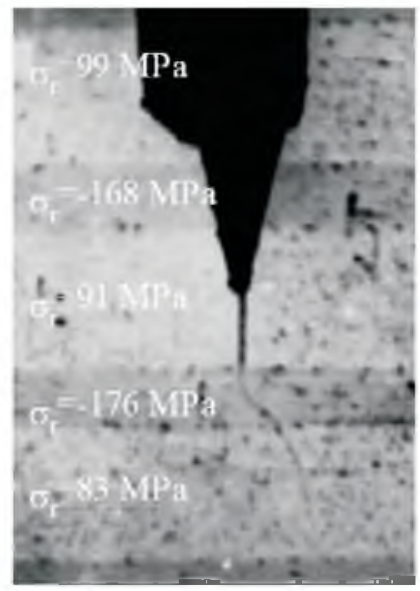

Fig. 4. Optical photograph of layered specimen with a typical notch tip.

A stiff load cell ensuring the rigid loading of specimens under three-point bending with a $16 \mathrm{~mm}$ span was used for mechanical tests [18]. This "“autonomous" cell is equipped with specific rigid dynamometer providing an 
ultimate load of $2000 \mathrm{~N}$ with a specimen deflection measuring system using a deflectometer suspended on the specimen. The testing machine used is designed only for the displacement of a loading crosshead and control of its speed. To study $R$-curve effect the compliance technique was used. Notched specimen was placed into the hard load cell. Then loading of the specimen was performed up to crack growth onset followed by unloading. In addition to recording of the load-deflection diagrams, after each unloading of specimen, its polished lateral surface was examined by an optical microscope $(\times 1000)$ to measure crack length. After measurement of crack length the next loading-unloading cycle was made. The operations were repeated up to the total failure of specimen. Apparent fracture toughness was calculated by using expressions (12), (23), and (24).

Results and Discussion. Asymmetric structure of layered specimens under study results in linear variation of residual stresses within each layer. The critical issue to analyze fracture behavior of laminates is a choice of the coordinate system. Calculated values of apparent fracture toughness $K_{\text {app }}$ in layered specimens under study are analyzed depending on crack length parameter $\tilde{a}$, where $\tilde{a}=Y(\alpha) a^{1 / 2}$. The crack length parameter $\tilde{a}$ is the most appropriate to demonstrate critical conditions of crack growth. One of advantages of this parameter is that the stress intensity factor of an edge crack for fixed value of the applied stress $\sigma_{m}$ is depicted in the coordinate system $K_{a p p}-\widetilde{a}$ as a straight line from the coordinate origin. Indeed, it follows from (22) that $K_{1}=\sigma_{m} \tilde{a}$, therefore, the slope of straight line equals to the applied stress $\sigma_{m}$. The conditions for unstable crack growth in the internal stress field are as follows [9]: $K_{1}\left(\sigma_{m}, a\right)=K_{a p p}(a), d K_{1}\left(\sigma_{m}, a\right) / d a \geq d K_{a p p}(a) / d a$. Using parameter $\widetilde{a}$, these conditions become: $\sigma_{m} \widetilde{a}=K_{a p p}(\widetilde{a}), \sigma_{m} \geq d K_{a p p}(\widetilde{a}) / d \tilde{a}$. The last two conditions can be reduced to:

$$
K_{a p p}(\widetilde{a}) / \widetilde{a} \geq d K_{a p p}(\widetilde{a}) / d \widetilde{a} .
$$

It follows from Eq. (26) and Fig. 5 [9] that unstable crack growth occurs if the slope of straight line corresponding to the stress intensity factor at constant applied stress is no less than the slope of tangent line to the fracture resistance curve at the same point.

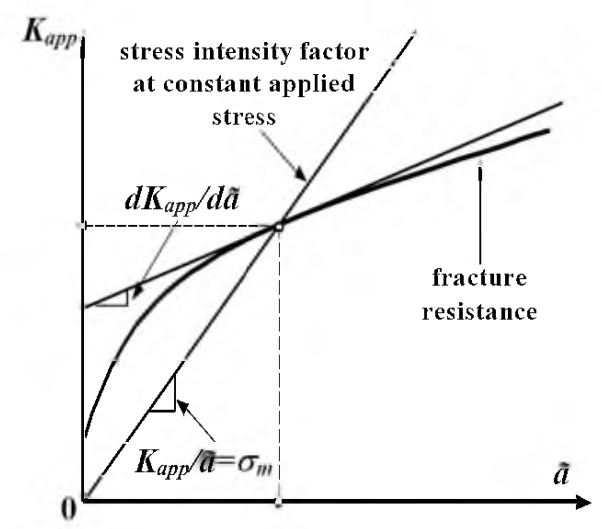

Fig. 5. Condition of unstable crack growth in the internal stress field. 
Figure 6 shows dependence of the apparent fracture toughness on crack length parameter $\widetilde{a}$ in laminate $\mathrm{Si}_{3} \mathrm{~N}_{4} / \mathrm{Si}_{3} \mathrm{~N}_{4}-20 \mathrm{wt} . \%$ TiN, specimen 1 (solid curve). The areas corresponding to compressive and tensile layers are shown in gray and white, respectively. The fracture toughness of layer material is shown as horizontal straight line. The dependence of apparent fracture toughness on $\widetilde{a}$ is non-monotonous. The apparent fracture toughness increases in the compressive layers and decreases in the tensile layers. The peak values of $K_{\text {app }}$ correspond to interfaces between layers. The apparent fracture toughness of the layered composite varies from 2 to $10 \mathrm{MPa} \cdot \mathrm{m}^{1 / 2}$ depending on the crack length. The initial notch tip is in tenth layer that is under residual tension. Measured value of the apparent fracture toughness corresponding to the initial notch is $5.57 \mathrm{MPa} \cdot \mathrm{m}^{1 / 2}$ that is in accord with the calculated value. Unloading was made after small advance of crack from the initial notch. Crack arrest occurred in the 12th layer of specimen. The length of arrested crack was measured. Then the next loading resulted in the total failure of specimen. Measured value of the apparent fracture toughness corresponding to arrested crack is $7.42 \mathrm{MPa} \cdot \mathrm{m}^{1 / 2}$ that is also in accord with the calculated value.

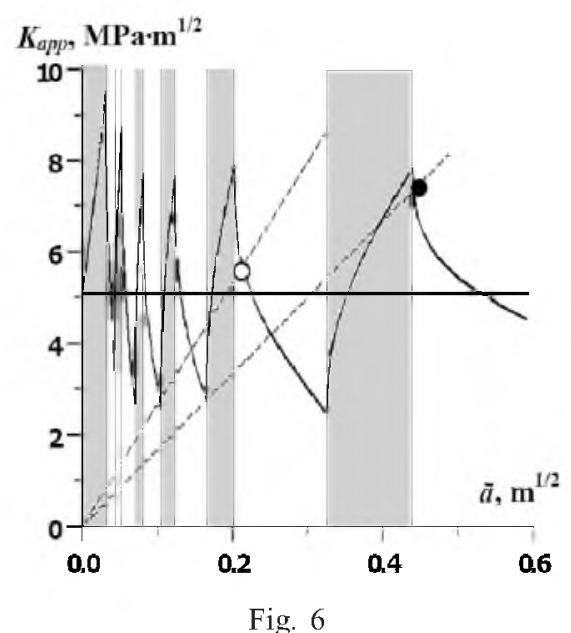

Fig. 6

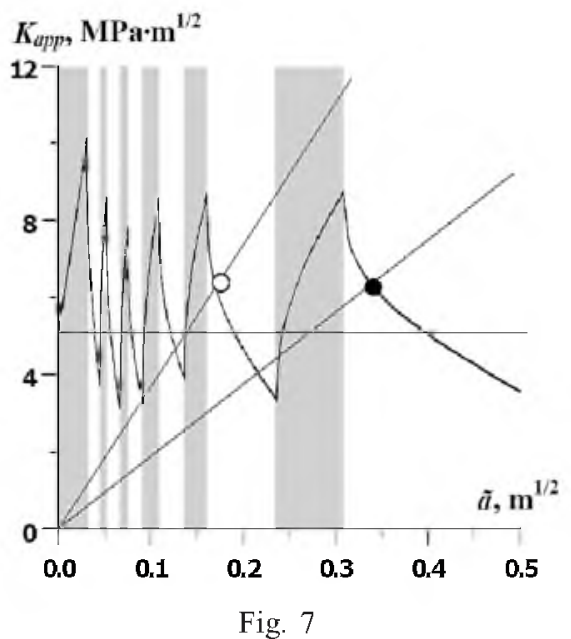

Fig. 7

Fig. 6. Dependence of the apparent fracture toughness on the crack length parameter $\tilde{a}$ in laminate $\mathrm{Si}_{3} \mathrm{~N}_{4} / \mathrm{Si}_{3} \mathrm{~N}_{4}-20$ wt. \% TiN (specimen 1). Areas of compressive layer are shown in grey. Solid curve is the calculated dependence, horizontal line is the fracture toughness of layer material. Dashed line is the stress intensity factor at constant applied stress of crack growth onset. Open circle corresponds to the initial notch, filled circle corresponds to arrested crack.

Fig. 7. Dependence of the apparent fracture toughness on the crack length parameter $\tilde{a}$ in laminate $\mathrm{Si}_{3} \mathrm{~N}_{4} / \mathrm{Si}_{3} \mathrm{~N}_{4}-20$ wt.\% TiN (specimen 2). Designations are the same as in Fig. 6.

Figure 7 shows dependence of the apparent fracture toughness on crack length parameter $\tilde{a}$ in specimen 2. Designations are the same as in Fig. 6. The dependence of the apparent fracture toughness on crack length parameter is non-monotonous as well. The fracture toughness behavior in compressive and tensile layers in specimen 2 is qualitatively similar to that in specimen 1 . However, difference of specimen geometry results in some difference of the apparent fracture toughness range. Specifically, the apparent fracture toughness of 
specimen 2 varies from 3 to $11 \mathrm{MPa} \cdot \mathrm{m}^{1 / 2}$. The initial notch tip in the specimen is also in tenth layer that is under residual tension. In this case, measured value of the apparent fracture toughness corresponding to the initial notch is $6.39 \mathrm{MPa} \cdot \mathrm{m}^{1 / 2}$. That is in accord with the calculated value too. After unloading crack was arrested in 12th layer like specimen 1 . Specimen 2 with arrested crack demonstrates the apparent fracture toughness value of $6.27 \mathrm{MPa} \cdot \mathrm{m}^{1 / 2}$. This is in good accord with the calculated value.

Additionally to $\mathrm{Si}_{3} \mathrm{~N}_{4} / \mathrm{Si}_{3} \mathrm{~N}_{4}-20 \mathrm{wt} . \%$ TiN layered specimens, the mechanical behavior of $\mathrm{Si}_{3} \mathrm{~N}_{4} / \mathrm{Si}_{3} \mathrm{~N}_{4}-70$ wt.\% TiN laminates was studied by the compliance technique. Figure 8 shows cyclic load - displacement diagram of layered specimen $\mathrm{Si}_{3} \mathrm{~N}_{4} / \mathrm{Si}_{3} \mathrm{~N}_{4}-70$ wt.\% TiN with crack. An interesting feature of this diagram is a number of hysteresis loops recorded during specimen unloading and its further loading. It can be connected with some energy dissipation during unloading-loading cycle. A similar effect was also observed, e.g., in the studies of $R$-curves for graphite [19]. It was connected with the amount of energy dissipated by plastic strains. The microscopic analysis of fractured specimens demonstrated that tensile-stressed layers containing $70 \%$ TiN display multiple channel cracks formed during specimen sintering that is probably due to the insufficient strength of these layers. However, the propagating crack, fracturing the specimens, did not always pass through channel cracks. It was established that specimens of such composition layer cracks did not practically propagate in the direction of loading, and they did not even always start from the tip of a V-notch. As a whole, the fracture pattern of $\mathrm{Si}_{3} \mathrm{~N}_{4} / \mathrm{Si}_{3} \mathrm{~N}_{4}-70 \mathrm{wt} \%$ TiN specimens appeared to be very. Therefore, theoretical analysis and calculation of the apparent fracture toughness - crack length dependence of such laminates was not carried out in the present work. To describe crack behavior in layered specimens containing 70\% TiN in tensile layer properly, it is necessary to take into account contributions of such factors as crack branching, microcracking, multiple channel cracks formation, crack kinking etc.

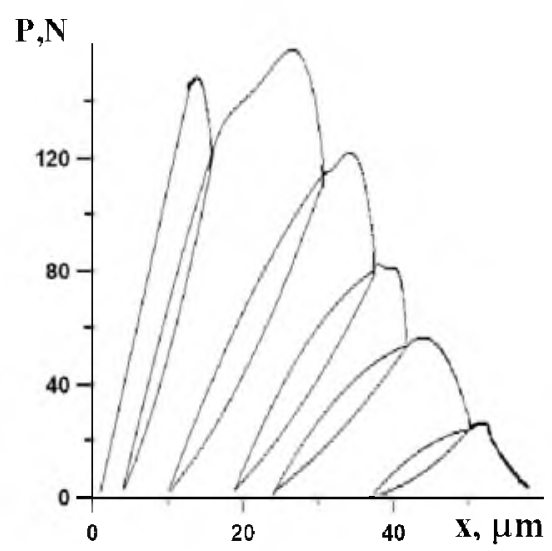

Fig. 8. Cyclic load - displacement diagram of layered specimen $\mathrm{Si}_{3} \mathrm{~N}_{4} / \mathrm{Si}_{3} \mathrm{~N}_{4}-70$ wt.\% TiN with crack.

Let us consider some features of crack arresting in our experiments. Open circle $A$ in Fig. 9 designates the initial state of testing: initial notch without 
loading. Open circle $B$ corresponds to the crack growth onset at some critical applied stress. Open circles depict the initial notch with length $a_{0}$. Filled circle $C$ corresponds to the onset of unloading. Note that the applied stress increases permanently during the loading stage (from $A$ to $C$ in Fig. 9), while the crack starts to grow only if the applied stress intensity factor exceeds the apparent fracture toughness (from $B$ to $C$ in Fig. 9). The crack growth under unloading can vary depending on the rate of the applied stress decreasing. Schematically it is shown in Fig. 9 by two paths of crack development $(C-D-E-F$, Fig. 9a; and $C-D^{\prime}-E^{\prime}-F^{\prime}$, Fig. 9b). Curve $C-D^{\prime}-E^{\prime}-F^{\prime}$ corresponds to a higher rate of the applied stress reduction. Filled circles $D$ and $D^{\prime}$ characterize current positions of moving crack tip under unloading. Filled circles $E$ and $E^{\prime}$ designate the crack arresting when applied crack intensity factor becomes less than the apparent fracture toughness. Filled circles $F$ and $F^{\prime}$ depict the final state of crack with length $a_{f}$ (or $a_{f}^{\prime}$ ) after full unloading. One can see from Fig. 9 that different unloading conditions can result in various distance passed by the crack. If $C-D-E-F$ path is realized, the crack is arrested in the next tensile layer (Fig. 9a). If $C-D^{\prime}-E^{\prime}-F^{\prime}$ path is realized the crack is arrested in the nearest compressive layer (Fig. 9b). In the general case, unloading conditions can result in a number of various final positions of the crack tip. It can be either in the layer with the initial notch tip or in any more remote layer. Revisiting our experimental data we note that $C-D-E-F$ path rather than $C-D^{\prime}-E^{\prime}-F^{\prime}$ is realized in the laminate specimens.

In such a way, we have two stages of the loading process and three stages of crack development. The first stage of loading process is the applied stress increasing to some maximum value (from $A$ to $C$ in Fig. 9a). The second stage of loading process is the applied stress decreasing to zero (from $C$ to $F$ in Fig. 9a). The first stage of crack development is the absence of crack growth until applied stress intensity factor is less than apparent fracture toughness (from $A$ to $B$ in Fig. 9a). The second stage of crack development is the crack growth (from $B$ to $E$ in Fig. 9a). The third stage of crack development is the absence of crack growth if the applied stress intensity factor is less than the apparent fracture toughness again (from $E$ to $F$ in Fig. 9a).
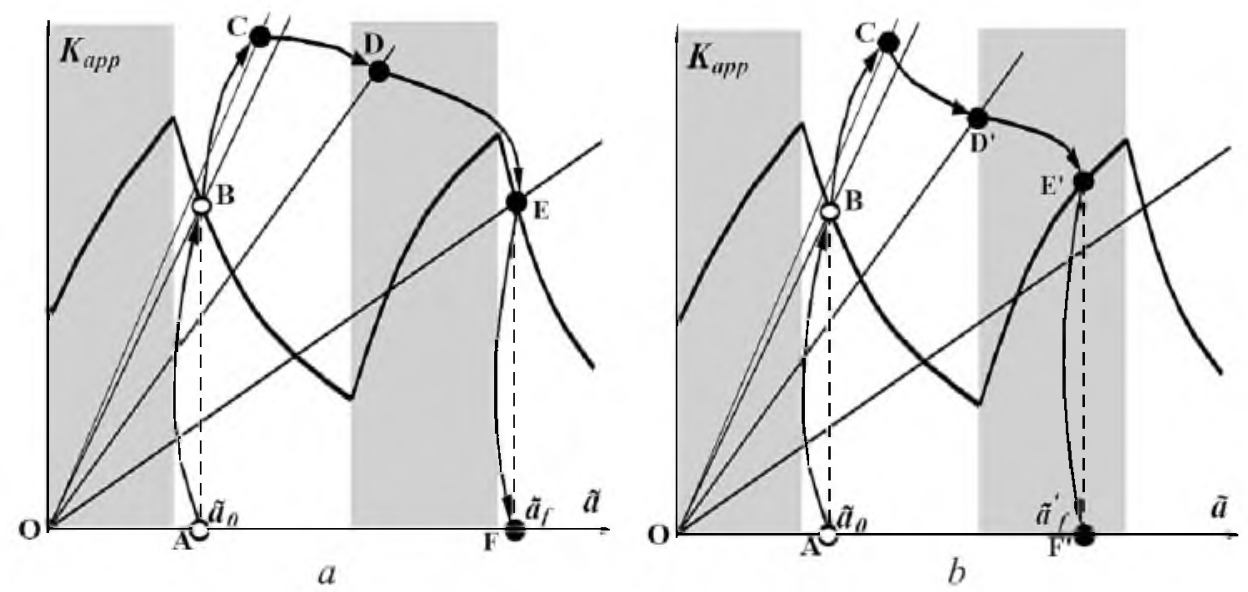

Fig. 9. Stages of crack arresting in layered specimen: (a) crack is arrested in the tensile layer; (b) crack is arrested in the compressive layer. 
The condition for stable crack growth in the residually stressed layers can be obtained from (26). The stable crack growth can occur when $K_{a p p}(\tilde{a}) / \widetilde{a}<$ $<d K_{a p p}(\tilde{a}) / d \widetilde{a}$. As the condition is satisfied, the load decreasing results in indispensable crack arresting. The crack arrest under stable growth conditions differs from features of crack arresting described in our work. This is due to the fact that unstable crack growth was observed for the layered specimens investigated. Crack arrest does not depend on the unloading rate under conditions of stable crack growth. A crack will be arrested in any case if the applied load would not increase. At the same time, crack arrest for unstable crack growth depends strongly on the stress decrease rate. The unloading rate is determined mainly by the stiffness of loading cell. The more the stiffness, the less crack path before arrest. It is evident that the stable crack growth leads to strengthening and to strength insensitiveness to the initial flaw size. In a layered material design process, it is necessary to determine the range of stable crack growth and strengthening if the range of flaws in layers is known. Usually, technological flaws are relatively small in laminates. Only rising dependence of the apparent fracture toughness on the crack length is not sufficient to obtain the desirable strengthening and toughening. The dependence is effective in imparting flaw tolerance only if the slope of the apparent fracture toughness curve is steep at short crack lengths. Obtaining high residual compressive stress is an effective way to provide high toughness at small crack lengths, thereby ensuring the improved flaw tolerance and surface damage resistance.

Conclusions. The toughening of ceramic-matrix asymmetric laminates with elastic inhomogeneity has been studied both analytically and experimentally. Applied and residual stress distributions are determined for an arbitrary alteration of different layers. Expression for the apparent fracture toughness of residuallystressed asymmetric layered material is obtained. The most appropriate coordinate system to analyze fracture conditions of laminar composite is shown to be the system where the apparent fracture toughness is depicted depending on the crack length parameter $\widetilde{a}=Y(\alpha) a^{1 / 2}$. The dependences of the apparent fracture toughness on the crack length parameter are calculated for the specimens under study. Conditions of crack arrest, stable and unstable crack growth in layered structure are analyzed. It is shown that the path passed by the crack before arrest can vary depending on the stiffness of loading cell. The experimental values of the apparent fracture toughness are measured using the compliance technique. They are in good agreement with the calculated data.

\section{Резюме}

Розглядається вплив залишкових напружень на опір руйнуванню і зупинку тріщини в несиметричних шаруватих структурах $\mathrm{Si}_{3} \mathrm{~N}_{4} / \mathrm{Si}_{3} \mathrm{~N}_{4}-\mathrm{TiN}$. Проаналізовано методику визначення $R$-кривих пшаруватих композитів із використанням методу піддатливості. Розроблено аналітичний метод розрахунку залежності опору руйнуванню від довжини тріщини в шаруватих структурах, що мають шари 3 різними пружними характеристиками. Застосовність методу перевірено шляхом розрахунку коефіцієнтів інтенсивності напружень для шаруватих зразків із крайовою тріщиною. Отримані результати зіставляються 3 даними механічних випробувань. 
1. M. Chan, "Layered ceramics: processing and mechanical behavior," Ann. Rev. Mater. Sci., 27, 249-282 (1997).

2. W. J. Clegg, K. Kendall, N. McN Alford, et al., "A simple way to make tough ceramics," Nature, 347, 455-457 (1990).

3. R. Lakshminarayanan, D. K. Shetty, and R. A. Cutler, "Toughening of layered ceramic composites with residual surface compression," J. Amer. Ceram. Soc., 79, No. 1, 79-87 (1996).

4. M. Lugovy, N. Orlovskaya, V. Slyunyayev, et al., "Crack bifurcation features in laminar specimens with fixed total thickness," Comp. Sci. Tech., 62, 819-830 (2002).

5. D. B. Marshall, J. J. Ratto, and F. F. Lange, "Enhanced fracture toughness in layered microcomposites of $\mathrm{CeO}-\mathrm{ZrO}_{2}$ and $\mathrm{Al}_{2} \mathrm{O}_{3}$," J. Amer. Ceram. Soc., 74, No. 12, 2979-2987 (1991).

6. M. Lugovy, N. Orlovskaya, K. Berroth, and J. Kuebler, "Macrostructural engineering of ceramic-matrix layered composites," Comp. Sci. Tech., 59 , 1429-1437 (1999).

7. A. J. Blattner, R. Lakshminarayanan, and D. K. Shetty, "Toughening of layered ceramic composites with residual surface compression: effects of layer thickness," Eng. Fract. Mech., 68, 1-7 (2001).

8. A. G. Evans, "Perspective on the development of high-toughness ceramics," J. Amer. Ceram. Soc., 73, No. 2, 187-206 (1990).

9. V. M. Sglavo, L. Larentis, and D. J. Green, "Flaw-insensitive ion-exchanged glass: I, theoretical aspects," Ibid, 84, No. 8, 1827-1831 (2001).

10. R. J. Moon, M. Hoffman, J. Hilden, et al., "Weight function analysis on the $R$-curve behavior of multilayered alumina-zirconia composites," Ibid, $\mathbf{8 5}$, No. 6, 1505-1511 (2002).

11. T. Fett and D. Munz, "Influence of crack-surface interactions on stress intensity factor in ceramics," J. Mater. Sci. Lett., 9, 1403-1406 (1990).

12. S. P. Timoshenko and J. N. Goodier, Theory of Elasticity, 3rd edn., McGraw-Hill, New York (1970).

13. A. E. Giannakopoulos, S. Suresh, M. Finot, and M. Olsson, "Elastoplastic analysis of thermal cycling: layered materials with compositional gradients," Acta Metall. Mater., 43, No. 4, 1335-1354 (1995).

14. V. Sergo, D. M. Lipkin, G. de Portu, and D. R. Clarke, "Edge stresses in alumina/zirconia laminate," J. Amer. Ceram. Soc., 80, No. 7, 1633-1638 (1997).

15. J. E. Srawley, "Wide range stress intensity factor expressions for ASTM E 399 standard fracture toughness specimens," Int. J. Fract., 12, 475-476 (1976).

16. N. A. Orlovskaya, J. Kuebler, V. I. Subotin, and M. I. Lugovy, "High Toughness Ceramic Laminates by Design of residual Stresses," in: F. T. Wallenberger, N. Weston, K. Chawla, R. Ford, and R. P. Wool (Eds.), 2001 Fall Meeting Proceedings, Vol. 702 (2001). 
17. T. Hyatt, "Electronics: Tape casting, roll compaction," Amer. Ceram. Soc. Bull., 74, 56-59 (1995).

18. G. A. Gogotsi, "Fracture toughness studies on ceramics and ceramic particulate composites at different temperatures," in: J. A. Salem, G. D. Quinn, and M. G. Jenkins (Eds.), Fracture Resistance Testing of Monolithic and Composite Brittle Materials, ASTM STP 1409, West Conshohocken, PA (2002), pp. 199-212.

19. M. Sakai, K. Urashima, and M. Inagaki, "Energy principle of elastic-plastic fracture and its application to the fracture mechanics of a polycrystalline graphite," J. Amer. Ceram. Soc., 66, No. 12, 868-874 (1983).

Received 12.06. 2003 